\title{
Comparison of the Residual Income and the Pricing - Multiples Equity Valuation Models
}

\author{
Georgia Pazarzi ${ }^{1}$
}

\begin{abstract}
:
The paper aims at analyzing the performance of two of the equity valuation models, the residual income (RIVM) and the pricing - multiples model. I test first how the residual income valuation model performs relative to the pricing - multiples model for a set of different value drivers and industries, second whether the performance of the different multiples increases when these are measured either with the mean, the median or the harmonic mean of the absolute prediction error and the signed prediction error.

The pricing - multiples approach is in most cases a better predictor of market prices than the residual income valuation model. In addition, the harmonic mean yields to more reliable estimates of value for a set of different industries. Finally, there are some value drivers that are supposed to be more reliable than others in specific industries, but there isn't any value driver that dominates all the industries.
\end{abstract}

\footnotetext{
${ }^{1}$ Phd Candidate Dept. of Maritime Studies, University of Piraeus, State Scholarships Foundation (IKY) Scholar
} 


\section{Related Literature}

The role of accounting numbers in equity valuation, independently of the valuation method used, is of great importance. Accounting data are believed to be associated with market prices and returns, a fact that is supported by the existing evidence. The literature on the link between accounting numbers and business' value consists of numerous research papers that provide evidence on the subject. Kothari (2001) cites the studies of Rayburn (1986), Bernard and Stober (1989), Bowen, Burgstahler and Daley (1986 and 1987), Livnat and Zarowin (1990) and Wilson (1986 and 1987), all of them indicating that there is association between stock returns, accruals and cash flows.

Another very important study that should be mentioned is that of Ohlson (1995), which relates prices or returns with accounting data using the residual income concept. The rationale for this relation is that the assets are separated in two categories in proportion to which item is used to determine the market value. The first category consists of those assets that use earnings to determine market value and the second of those that use book value to determine market value. Ohlson (1995) expressed returns in proportion to the level of earnings, the change in earnings, the dividends as well as other information. This facilitated understanding the relation between market prices and accounting information, although it has been

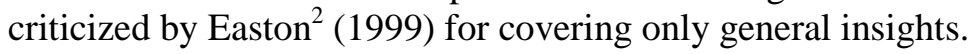

\subsection{Comparison of Various Multiples}

Frankel and Lee (1998), using the RIVM, test whether the resulting V/P ratio is a good predictor of cross-sectional stock returns. Their findings suggest that the predictability of the V/P ratio regarding stock returns is considerable and increases as the forecasting horizon becomes longer. Furthermore, their results do not change when beta, size and $\mathrm{B} / \mathrm{P}$ are taken into account, which shows the superior explanatory power of the RIVM.

Lee and Swaminathan (1999) use four pricing multiples, the B/P (book to price) ratio, the $\mathrm{E} / \mathrm{P}$ (earnings to price) ratio, the $\mathrm{D} / \mathrm{P}$ (dividends to price) ratio and the $\mathrm{V} / \mathrm{P}$ (value to price) ratio (V calculated with the RIVM) and test their ability to predict future prices and returns of the Dow Jones Industrial Average (DJIA). Running univariate regressions, they find that the V/P multiple is associated with future stock prices and DJIA index returns. In addition, multivariate regressions show that the $\mathrm{V} / \mathrm{P}$ multiple, derived from the RIVM is a better predictor of future returns for all horizons, comparing to the $\mathrm{B} / \mathrm{P}, \mathrm{E} / \mathrm{P}$ and $\mathrm{D} / \mathrm{P}$ multiples. Their results are consistent with those of Frankel and Lee (1998) in that the RIVM has reliable predictive power,

\footnotetext{
${ }^{2}$ Easton (1999) refers to other, more detailed studies concerning the relation between prices and accounting data, such as those of Feltham and Ohlson (1995), Basu (1997) and Zhang (1999). These three papers examine this relation when a firm's policies are conservative.
} 
as value estimates derived from this model track intrinsic value better than dividends, earnings or book value.

Liu, Nissim and Thomas (2002a) provide a more complete comparison of the relative and absolute performance of numerous multiples. They have considered multiples based on diverse measures, such as accrual flows (earnings to price, sales to price), accrual stocks (book to price), cash flows (EBITDA to price, operating cash flow to price), forward-looking data (one and two year ahead earnings forecasts to price), the RIVM (V/P following Lee and Swaminathan (1999)). The first three measures are based on historical data while on the contrary, the remaining two on forecasts. Moreover, all the multiples have been computed with the harmonic mean. Consistent with Lee and Swaminathan (1999), they observe that multiples based on the RIVM perform better than those based on historical data. However, they provide additional evidence that forward-looking earnings outperform the residual income based multiples, contradicting the conclusions of Lee and Swaminathan (1999). Finally, they go further, suggesting that among the multiples based on historical data, earnings are the best value estimates whereas all the others perform poorly.

Kim and Ritter (1999) focus on Initial Public Offerings (IPOs) and present analogous results. They conclude that valuation performance improves substantially when earnings forecasts are used, rather than historical earnings. They also agree with Alford (1992) that the valuation accuracy is superior for large firms than for small ones.

\subsection{Industry Multiples and Cross-country comparison}

The question whether there exist "preferred" multiples for valuation purposes in different industries is of great interest to academics and researchers. The evidence related to this issue is primarily linked to Tasker (1998) and Liu, Nissim and Thomas (2002b). Tasker (1998) examines the multiples used by investment bankers and observes that the ones most widely used are those based on book value, earnings per share (EPS), operating cash flow (OCF) and revenues. However, multiples differ from industry to industry due to differences in the accounting practices used. For example, for the banking industry, the preferable value drivers are book value and net income, and generally balance sheet measures, because the assets are well measured. In high-tech industries, such as software, only the revenues can serve as value drivers, for the reason that investments in $R \& D$ are immediately expensed and therefore earnings are meaningless. In capital-intensive industries like hotels, real estate and oils, an operating cash flow multiple is preferred to adjust for different non-cash charges (depreciation and amortization) across otherwise similar firms.

Liu et al. (2002b) test the association of industry multiples with the market prices and agree with Tasker (1998) that different industries use different multiples. The multiples examined are based on both reported and forecasted values of earnings, 
sales, dividends and operating cash flow and are computed with the harmonic mean ${ }^{3}$. Furthermore, Liu et al. (2002b) extend their research and compare industry multiples used across eight countries ${ }^{4}$. They observe the superiority of the multiples when industry comparables are used. In addition, they suggest that multiples vary across industries on an international basis, as a consequence of the different interpretation of the value drivers and the different industry classification in each country. More specifically, different countries have different legal systems regarding the financial and tax accounting, the protection of shareholders, as well as the use of accrual accounting, fact that provokes variations across countries in the performance of the diverse multiples.

Consistent with the conception that multiples vary across industries, Baker and Ruback (1999), in their effort to compare the DCF and the pricing-multiples valuation methods, conclude that there isn't a single multiple that performs well in all the industries.

\subsection{Comparison of Valuation Methods}

There are basically two studies that compare the performance of forecast-based models derived from the Discounted Dividend Model (DDM). These include an analysis conducted by Penman and Sougiannis (1998) and another one by Francis, Olsson and Oswald (2000). These two papers are very similar in their tests and their findings, though there are some differences between them. Both the two papers examine the reliability of intrinsic value estimates computed with three valuation models: the Discounted Dividend Model (DDM), the Free Cash Flow (FCF) model and the RIVM. The main dissimilarities of the papers consist of the use of different measures of performance and the interpretation of payoffs. Penman and Sougiannis (1998) use the absolute pricing error (APE) to test the accuracy of alternative value estimates whilst Francis et al. (2000) test also the bias (through the signed prediction error - SPE) and the explainability $\left(\mathrm{R}^{2}\right)$ of the estimates. In addition, Penman and Sougiannis (1998) use only realizations of the payoff attributes subsequent to time $t$ as though they were forecasts at time $t$ (they assume perfect knowledge of the future), whereas Francis et al. (2000) use forecasted payoff attributes. Their results are quite interesting. Even though the three models examined derive from the same model (DDM), so theoretically they must yield the same estimates, both papers suggest that the RIVM performs better than the dividend and the free cash flow models. Francis et al. (2000) extend their analysis and find no evidence that the various accounting practices (such as the interpretation of $R \& D$ expenditures or the level of discretion) have a negative impact on the reliability of the value estimates.

\footnotetext{
${ }^{3}$ Exactly the same as in their previous paper (2002a)

${ }^{4}$ Australia, Canada, France, Germany, Japan, Taiwan, UK and US
} 
The above discussed views have been the subject of critique by Lundholme and O' Keefe (2001), who disapprove the superiority of the RIVM over the Discounted Cash Flow (DCF) model, as supported by Penman and Sougiannis (1998) and Francis et al. (2000). They suggest that since both models derive from the same underlying assumption (price is the present value of expected future dividends, discounted at the cost of equity capital), any differences in the value estimates computed with these models, is due to inconsistencies in the application of the model. More specifically, they identify three types of errors: 1 . the inconsistent forecasts error, caused by wrongly hypothesizing the same assumptions for the terminal values for the two models (i.e. for the growth rate), 2. the incorrect discount rate error, which occurs when the equity value is computed by subtracting the debt from the value of the firm that is discounted using a Weighted Average Cost of Capital (WACC), and 3. the missing cash flow error, caused by violations of the Clean Surplus Relationship (CSR) in the RIVM. From the other side, Penman supports that the need to make finite horizon forecasts provokes the superiority of accounting-based approaches (such as the RIVM) over cash-based models.

Gilson, Hotchkiss and Ruback (2000) compare as well the predictability of the DCF and the pricing multiple models, when valuing business in financial distress. The value driver used in the pricing-multiples model is the earnings before interest, taxes, depreciation and amortization (EBITDA). They observe that value estimates are in general unbiased, though they are not very precise, as indicated by the wide dispersion of pricing-errors. This, they recommend, can be explained by two reasons: the limited amount and quality of information due to the bankruptcy process, as well as the strategic distortion of the cash flows, linked to the incentives of the participants to deform value.

Similar analysis has also been conducted by Kaplan and Ruback (1995), but for a sample consisting high-levered transactions. They compare the performance of 6 value estimates, three derived from the DCF model and three from the multiples model, using EBITDA as value driver. Contrary to Gilson et al. (2000), their results indicate no better valuation accuracy of either the DCF or the EBITDA multiples approach. This good performance of the DCF model is, according to them, the result of possible systematic and material cash flow adjustments made by the dealmakers.

\section{Empirical Analysis}

\subsection{Sample Selection and Data Sources}

The data was obtained from Datastream. The original data consisted of all the UK firms included in the FTSEALL apart from the financial institutions and the real estate firms for the period 31/12/2001 to 31/12/2002, a total sample of 1241 firms. The sample is reduced to 473 companies as I include only those firms that have positive and available values of current adjusted (Datastream item 211) and one and 
two-year ahead forecasted earnings (Datastream items EPS1 and EPS2 respectively). I also eliminate the companies that have zero or negative closing shareholders' funds (item 1107), EBITDA (item 1502) and operating cash flows (OCF, item 1015), and the sample includes now 429 firms. The constraints of positive values for the parameters above is necessary, as these include the value drivers of the pricingmultiples and must always be positive, otherwise the multiples cannot be defined. Firms whose dates of forecasted earnings per share do not match with the closing balance sheet dates are excluded, as their estimated values won't be reliable. Moreover, I classify the firms in industries based on INDC4 and exclude those industries for which the number of companies is less than eight, in order to have enough observations in each industry. The final sample contains $326 \mathrm{UK}$ firms divided into 17 industries, whose closing balance sheet date is in the period interval from 31/12/2001 to 31/12/2002. Table 1 below presents the number of cases affected and the size of the remaining sample when this is adjusted for the necessary restrictions.

Table 1.

\begin{tabular}{l|cc}
\hline CRITERIA & COMPANIES EXCLUDED & REMAINING FIRMS \\
\hline EPS $>0$ (211) & 493 & 748 \\
EPS $1>0$ & 246 & 502 \\
EPS $2>0$ & 29 & 473 \\
SF $>0$ (1107) & 11 & 462 \\
EBITDA>0 (1502) & 18 & 444 \\
OCF $>0$ (1015) & 15 & 429 \\
LYE=EPS1D & 64 & 365 \\
FIRMS IN EACH & 39 & 326 \\
INDUSTRY>7 & &
\end{tabular}

The table presents the number of firms excluded from and remained in the original sample when this is adjusted for the constraints. Column 1 shows the conditions required concerning several items (whose Datastream codes are in brackets), column 2 the number of firms excluded and column 3 the number of the firms remaining in the sample after each adjustment. EPS is the adjusted earnings per share, EPS1 and EPS2 the 1 and 2 year ahead forecasted earnings per share, SF the total closing shareholders' funds, EBITDA the earnings before interest, taxes, depreciation and amortisation, OCF the operating cash flow, LYE the closing balance-sheet date and EPSID the date of the earnings forecasts one year ahead.

\subsection{Methodology}

In order to calculate the intrinsic values at the balance sheet date of the firms included in my sample and compare them with their market prices, I need to make 
some adjustments. Firstly, for the 17 companies whose beta values are not available, I consider the industry beta average as their beta. Secondly, I change some balance sheet dates to the closest date for which prices and number of shares are available ${ }^{5}$. This adjustment is crucial as to ensure comparability of the estimated and the observed price values.

The formula used to calculate the intrinsic values with the RIVM is as follows:

$V_{t}^{e}=B V_{t}^{e}+\sum_{k=1}^{\infty} \frac{\mathrm{E}_{t}\left[N I_{t+k}-r_{e} B V_{t+k-1}^{e}\right]}{\left(1+r_{e}\right)^{k}}$

where:

$B V_{t}^{e}:$ the book value of the firm's assets at time $\mathrm{t}$

$N I_{t+k}$ : net income at time $\mathrm{t}+\mathrm{k}$

$r_{e}:$ the cost of equity capital

$\mathrm{E}_{t}:$ the expected value at time $\mathrm{t}$

The computation procedure is discussed in detail below. Firstly, I estimate the present value of the residual income for the first 2 years. The closing book value per share at year $0\left(\mathrm{BV}_{0}\right)$ is calculated as follows:

$B V_{0}^{e}=S F-$ PreferrenceShares + Div.Payable

where:

$B V_{0}^{e}$ : closing book value per share at year 0 , converted to a per share basis when divided by the number of shares at the balance sheet date (Datastream item IC) SF : total closing shareholders' funds per share PreferrenceShares : the preference capital (Datastream item 306)

Div.Payable : the ordinary dividends payable (Datastream item 382)

The book values for the next two years derive from the clean surplus relationship:

$B V_{t+1}^{e}=B V_{t}^{e}+E P S_{t+1}-D I V_{t+1}$

where:

5 Specifically, I replaced 31/03/2002, 30/06/2002, 31/08/2002 and 30/11/2002 with 29/03/2002, 28/06/2002, 30/08/2002 and 29/11/2002 respectively. 
$B V_{t}^{e}$ : book value at time t. This figure is converted to a per share basis when divided by the number of shares at the balance sheet date (Datastream variable IC). EPS $_{t+1}$ : earnings per share at period $\mathrm{t}+1$ (Datastream item EPS1)

$D I V_{t+1}$ : dividends at period $\mathrm{t}+1$, where dividends are the product of $E P S_{t+1}$ and the dividend payout ratio. The dividend payout ratio is computed as: Dividends per share/Current EPS (190/211 items from Datastream). The dividend payout ratio cannot exceed the value of 1 for the reason that the company can't pay its shareholders more than it earns. Hence, I change the values of the dividend payout ratio to 1 for the 33 companies whose the dividend payout ratio is larger than 1 .

All the accounting numbers are computed in pence so as to assure comparability with the share prices.

For more than 2 years horizon I calculate the terminal value of the residuals, assuming it to be a growing perpetuity. I choose a growth rate of the residuals of $2 \%$ because the UK growth rate is expected to be between $2 \%$ and $2.5 \%$, and I perform sensitivity analysis for growth rates of $1 \%$ and $3 \%$. The growth rate has to be less than the cost of capital in order for the terminal value to be defined. For this reason I replace 3 terminal values that cannot be defined with zero. In addition, I replace the negative terminal values (which indicates that the residual income at period 2 is negative) of 61 companies with zero, because that negative residuals are not supposed to persist.

Besides, the cost of capital that appears in the formula is derived from the Capital Asset Prising Model (CAPM). The relevant formula is:

$r_{e}=r_{f}+\beta *\left(r_{m}-r_{f}\right)$

where:

$r_{e}:$ the cost of equity capital

$r_{f}:$ the risk free rate

$\beta$ : the firm's beta (Datastream item BETA)

$r_{m}-r_{f}:$ the equity risk premium

The risk free rate derives from the annualised 3-month Treasury Bill discount rate of the date that is closest to the balance sheet closing date, which is obtained from Datastream (program 900B, item LNDTB3M). The discount rate converts into an effective annual rate of return using the formula:

\footnotetext{
${ }^{6}$ http://edition.cnn.com/2003/BUSINESS/04/09/uk.budget/ (CNN website)
} 


$$
r_{f}=\left(1+r_{3 m}\right)^{(365 / 91)}-1
$$

where:

$$
r_{3 m}=\frac{d\left(\frac{91}{365}\right)}{\left[1-d\left(\frac{91}{365}\right)\right]}
$$

\section{d : the 3-month Treasury Bill discount rate}

The equity risk premium is difficult to observe and has been the subject of debates between analysts and academics. Most of them use arbitrarily a value of risk premium (e.g.5\%) and test how the results change for different values of risk premium. I use a risk premium of $5 \%$ because the UK equity risk premium is thought to be between $4 \%$ and $5 \%^{7}$ and I perform sensitivity analysis of values of $4 \%$ and $6 \%$.

Concerning now the pricing-multiples approach, the general formula of the model is:

$$
V_{i}=V D_{i} * \text { average }_{j \in \Phi}\left[\frac{P_{j}}{V D_{j}}\right]
$$

where:

$V_{i}$ : the estimated value of the firm $\mathrm{i}$

$V D_{i}$ : the value driver, that is, a selected performance driver of the firm (for example earnings, book value or sales among others). The value driver must always have positive value.

$P_{i}$ : the observed price for the $\mathrm{j}^{\text {th }}$ comparator firm

$\Phi_{i}$ : the set of comparable firms for firm $\mathrm{i}$

The value drivers I examine are current earnings per share (EPS), one-year ahead forecasts (EPS1), book value per share (BV), EBITDA per share, operating cash flows per share $(\mathrm{OCF})$ as well as intrinsic value per share $(\mathrm{V})^{8}$. Value $(\mathrm{V})$ is the intrinsic value of the firm calculated with the RIVM. Book value per share is the closing book value divided by the number of shares (Datastream item IC). The

\footnotetext{
${ }^{7}$ According to evidence reported by Dimson, Marsh and Staunton (2003) and John O'Hanlon and Anthony Steele (2000).

${ }^{8}$ Similar to those examined by Liu et al. (2002a).
} 
remaining value drivers are converted in a per share basis if divided by the weighted average number of shares in issue during the year, which equals:

WeightedAverageNo.OfShares $=\frac{\text { Datastreamtem } 210}{\text { Datastreamitem } 211}$

where :

Datastreamtem210: Earned for ordirary-Adjusted

Datastreantem211: Net earnings per share-Adjusted

The average of each of the above multiples is computed with the mean, the median and the harmonic mean, and is based on INDC4 as a comparator group. That means that for every company that belongs to a specific industry, the average multiple is computed as the mean, median or harmonic mean of all the companies of the industry apart from the particular firm whose value we want to estimate.

Each of the value drivers is combined with the market price (equity-level measure) 4 months after the balance sheet closing date, even the entity-level ones (EBITDA and OCF). The reason for following this approach is that when EBITDA and OCF are combined with debt plus equity yield less accurate estimates of value. Table 2 presents the average and median APE and SPE for the EBITDA and the OCF when these are combined with the entity value (debt plus equity) and the price. It is obvious that when EBITDA and OCF yield superior estimates when combined with the stock price than with the debt plus equity.

Table 2. Comparison of entity level value drivers when combined with entity and equity level measures

\begin{tabular}{rc|cccc}
\hline & & MULTIPLE & & & \\
& & EV/EBITDA & P/EBITDA & EV/OCF & P/OCF \\
\hline $\begin{array}{r}\text { AVERAGE } \\
\text { ACCURACY }\end{array}$ & MEDIAN & $83.79 \%$ & $51.06 \%$ & $108.19 \%$ & $65.38 \%$ \\
HARMEAN & $85.04 \%$ & $46.80 \%$ & $108.08 \%$ & $54.83 \%$ \\
MCCURACY & MEDIAN & $41.01 \%$ & $34.27 \%$ & $42.53 \%$ & $41.22 \%$ \\
MARMEAN & $45.67 \%$ & $34.02 \%$ & $51.17 \%$ & $40.43 \%$ \\
MEDIAN & MEAN & $38.16 \%$ & $37.70 \%$ & $49.09 \%$ & $46.96 \%$ \\
BVIAS & MEDIAN & $30.79 \%$ & $19.13 \%$ & $51.75 \%$ & $29.24 \%$ \\
HARMEAN & $12.36 \%$ & $3.10 \%$ & $27.57 \%$ & $4.05 \%$
\end{tabular}




\begin{tabular}{rc|cccc} 
MEDIAN & MEAN & $-2.40 \%$ & $22.30 \%$ & $15.70 \%$ & $27.35 \%$ \\
BIAS & MEDIAN & $-17.47 \%$ & $0.32 \%$ & $-17.61 \%$ & $0.15 \%$ \\
HARMEAN & $-36.13 \%$ & $-13.81 \%$ & $-36.10 \%$ & $-19.47 \%$ \\
\hline
\end{tabular}

This table presents the performance of the pricing-multiple model when EBITDA per share (earnings before interest, tax, depreciation and amortisation, Datastream item 1502) and OCF per share (operating cash flow, item 1015) are used as value drivers and when each of them is combined with entity and equity level measures. These value drivers are divided by the weighted number of shares (item 210/211) to give a per share figure. EV is the entity value per share of the firm, which equals the sum of the equity value and the debt. The equity value is the market capitalisation, that is the product of the number of shares (Datastream variable IC) and the stock price. The debt is the sum of the total loan capital (item 321), borrowings repayable within 1 year (item 309) and preference shares (item 306) minus cash and equivalents (item 375), divided by the weighted number of shares to be converted in a per share basis. $P$ is the stock price of the firm 4 months after the balance sheet date. Accuracy and Bias are the Absolute and Signed Prediction Errors respectively. In order for the value estimates found under the entity and the equity perspective to be comparable, I subtract from the value calculated with the entity measure the debt for each specific firm.

After calculating the intrinsic value of the companies of my sample, either with the RIVM or with the pricing-multiples approach, I compare these values with the share price. The stock price of each firm is measured 4 months after the balance sheet closing dates, for the reason that after the 4-month period, the firms' financial statements have been published and consequently prices reflect all the information of the previous fiscal year.

\section{Empirical Results}

The results of the tests I carried out include a comparison of the accuracy and bias of the different valuation methods for the various industries that comprise my sample, through the average Absolute Prediction Error (APE) and Signed Prediction Error (SPE) respectively. Between four evaluation measures ${ }^{9}$ I focus only on accuracy and bias for three reasons. Firstly, it is difficult to compare the $\mathrm{R}^{2}$ of different valuation models. Secondly, we don't have information concerning the distribution of the pricing errors, so I cannot use the Standard Deviation and Interquartile Range approach. And third, I am interested whether, and in what degree the value estimates computed with the various approaches under or out perform the market price.

\footnotetext{
${ }^{9}$ APE, SPE, $\mathrm{R}^{2}$, Standard Deviation and Interquartile Range
} 
The general model of the pricing errors approach is the following:

PricingError ${ }_{i}=\hat{P}_{i}-P_{i}$

where:

$\hat{P}_{i}:$ the estimated price for firm $\mathrm{i}$

$P_{i}:$ the observed price for firm i

It is obvious that this formula implies comparison of the market price with the price estimated using a valuation model. The first approach is the Absolute Pricing Error (APE), which is simply a scaled pricing error. The formula of the APE is as follows:

PricingError $r_{i}=\frac{\left|\hat{P}_{i}-P_{i}\right|}{P_{i}}$

In this case one can measure the accuracy of the model, without distinguishing between positive and negative valuation errors. The lower the absolute value of the error, the more accurate the estimates.

The second approach is the Signed Prediction Error (SPE), which differentiates positive and negative errors, and is a measure of bias. Positive (negative) pricing errors indicate underestimation (overestimation) of price. The formula for the SPE is presented below:

PricingError $r_{i}=\frac{\left(\hat{P}_{i}-P_{i}\right)}{P_{i}}$

\subsection{Performance of the RIVM}

Table 3 presents the average and median SPE and APE of the entire sample for the range of growth estimates and risk premiums.

Table 3. Average and Median SPE and APE for Different Growth Rates and Risk Premiums

\begin{tabular}{l|ccc}
\hline \multirow{2}{*}{ RISK PREMIUM } & \multicolumn{3}{|c}{$\mathrm{g}$} \\
\cline { 2 - 4 } & $\mathbf{1 \%}$ & $\mathbf{2 \%}$ & $\mathbf{3 \%}$ \\
\hline \hline
\end{tabular}




\begin{tabular}{rr|cc|cc|cc} 
& & SPE & APE & SPE & APE & SPE & APE \\
\cline { 2 - 7 } $\mathbf{4 \%}$ & AVERAGE & $54.43 \%$ & $70.28 \%$ & $71.85 \%$ & $85.67 \%$ & $100.37 \%$ & $112.16 \%$ \\
& MEDIAN & $36.47 \%$ & $45.97 \%$ & $50.22 \%$ & $53.09 \%$ & $75.61 \%$ & $75.61 \%$ \\
\cline { 2 - 6 } $\mathbf{5 \%}$ & AVERAGE & $40.18 \%$ & $60.66 \%$ & $53.13 \%$ & $71.55 \%$ & $73.48 \%$ & $89.87 \%$ \\
\cline { 5 - 7 } & MEDIAN & $22.07 \%$ & $41.78 \%$ & $32.83 \%$ & $46.55 \%$ & $49.62 \%$ & $53.92 \%$ \\
$\mathbf{6 \%}$ & AVERAGE & $28.87 \%$ & $53.78 \%$ & $38.77 \%$ & $61.92 \%$ & $53.84 \%$ & $74.98 \%$ \\
& MEDIAN & $13.21 \%$ & $38.05 \%$ & $18.66 \%$ & $43.49 \%$ & $31.60 \%$ & $46.15 \%$ \\
\hline
\end{tabular}

This table presents the average median bias and accuracy (SPE and APE respectively), for growth rates of 1, 2 and 3\% and risk premium of 4, 5 and $6 \%$.SPE is computed as $(\hat{P}-P) / P$ and APE as $|\hat{P}-P| / P$, where $\hat{P}$ is the estimated price using the RIVM and P is the observed stock price in the market.

Assuming a risk premium of 5\%, the accuracy and the bias of the RIVM worsen as the growth rate becomes larger. In general, when growth rates are increasing, the model follows similar direction, independently from the assumed risk premium (Figure 1 and 2). This is justified from the fact that the larger the growth rate, the larger the terminal value of the residuals and therefore, the more possible for the values to have been overestimated. Indeed, when the risk premium is $4 \%$, its reliability is questioned because, for all the possible combinations, both the average and the median of the SPE and APE have values higher than those obtained for a risk premium of $5 \%$. Finally, the results found for a $6 \%$ risk premium indicate that the model gives more accurate and unbiased value estimates than those derived for smaller values of risk premium. This can also be explained mathematically. The larger the risk premium, the larger is the cost of capital and therefore the smaller the present values of the residual income. Hence, the value estimates derived from the RIVM are less overestimated for larger values of the risk premium. 


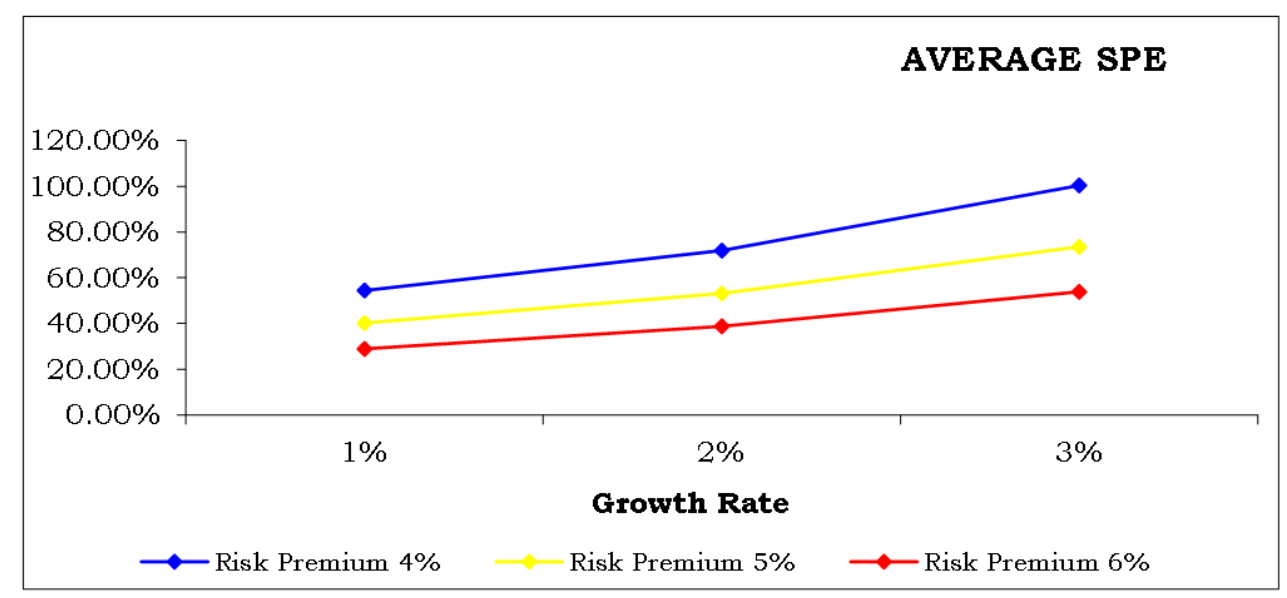

Figure 1. Average Signed Prediction Errors

Figure 1 and 2 present the average bias and accuracy of the RIVM for different growth rates and risk premiums, where it is obvious that the value estimates derived using the RIVM are not highly correlated with the market prices, fact that renders the reliability of the model doubtful ${ }^{10}$. This may be the result of the existence of a large number of outliers.

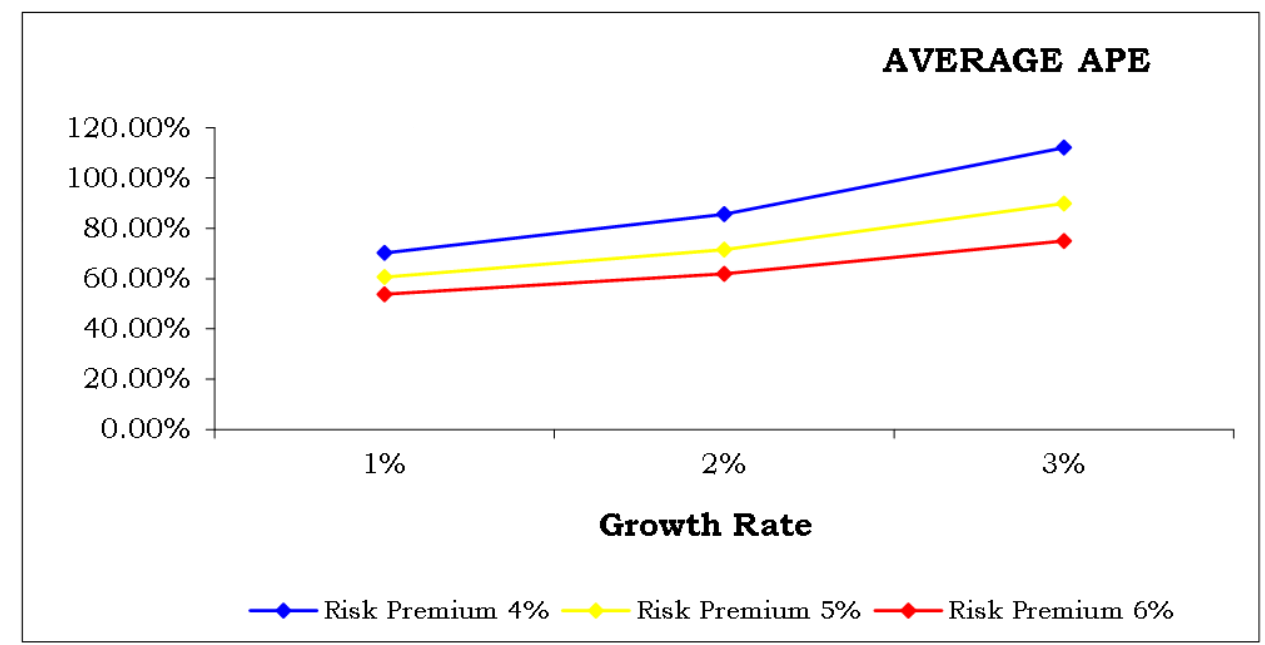

Figure 2. Average Absolute Prediction Errors

\subsection{Comparison of Mean, Median and Harmonic Mean}

${ }^{10}$ Appendix A shows the median bias and accuracy of the RIVM. 
Table 4 compares the average accuracy and bias of the values estimated using the mean, the median and the harmonic mean of each value driver. It is obvious that between these three, the harmonic mean gives the most reliable value estimates independently from the value driver used. From the other part, estimates computed with the mean are the less accurate, which can be explained from the fact that the mean is affected by extreme observations.

Table 4. Comparison of Mean, Median and Harmonic Mean of the Value Driver

\begin{tabular}{l|ccc|ccc}
\hline & \multicolumn{3}{|c|}{$\begin{array}{c}\text { APE } \\
\text { MEDIA }\end{array}$} & HARM. & \multicolumn{3}{c}{ SPE } \\
MULTIPLE & MEAN & N & MEAN & MEAN & MEDIAN & MEAN \\
\hline P/EPS & $124.33 \%$ & $58.92 \%$ & $55.33 \%$ & $103.96 \%$ & $27.96 \%$ & $8.79 \%$ \\
P/EPS1 & $51.49 \%$ & $40.59 \%$ & $36.61 \%$ & $31.99 \%$ & $11.40 \%$ & $1.47 \%$ \\
P/BV & $101.55 \%$ & $66.12 \%$ & $55.96 \%$ & $76.14 \%$ & $25.67 \%$ & $3.88 \%$ \\
P/EBITDA & $73.59 \%$ & $51.06 \%$ & $46.80 \%$ & $53.66 \%$ & $19.13 \%$ & $3.10 \%$ \\
P/OCF & $88.68 \%$ & $65.38 \%$ & $54.83 \%$ & $65.71 \%$ & $29.24 \%$ & $4.05 \%$ \\
P/V & $54.98 \%$ & $49.02 \%$ & $43.50 \%$ & $31.19 \%$ & $18.34 \%$ & $2.10 \%$ \\
\hline
\end{tabular}

The table presents the APE and SPE of different multiples computed with the mean, the median and the harmonic mean. APE is calculated as $|\hat{P}-P| / P$ and SPE as $(\hat{P}-P) / P$, where $\hat{P}$ is the estimated price using the specific pricing-multiple and $P$ is the observed stock price. The multiples considered are the P/EPS (price-toadjusted earnings per share), P/EPS1 (price-to-one year ahead earnings per share forecasts), $P / B V$ (price-to-book value per share), P/EBITDA (price-to-earnings before interest, tax, depreciation and amortisation per share), P/OCF (price-tooperating cash flow per share) and $P / V$ (price-to-value). $P$ is the observed stock price and $V$ is the intrinsic value estimated using the RI model. All the other variables are obtained from Datastream. EPS is the Datastream item 211, EPS1 is item EPS1, BV is the closing shareholders' funds (item 1107), EBITDA item 1502 and OCF item 1015. In order to convert the above Datastream items but BV in a per share basis, the weighted average number of shares was used, which is the quotient of the Datastream items 210/211. The BV was divided by the number of shares provided by Datastream (IC), to obtain the per share value.

The harmonic mean remains superior when examined for every industry separately, for whichever pricing multiple. In all the cases, the median has an intermediate performance and the mean provides estimates of poor quality, evidence that is easily observed in the figures 5 and 6. 


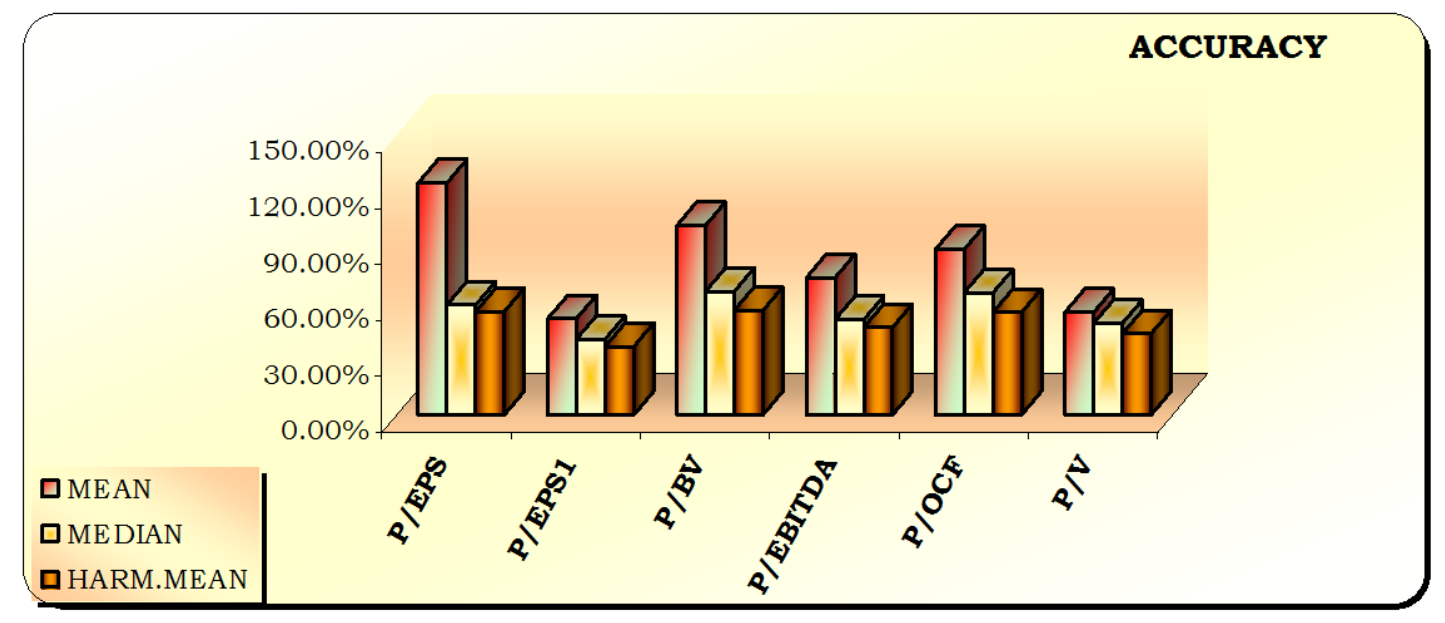

Figure 5. Comparison of the Average Accuracy of the Different Multiples, computed with the Mean, Median and Harmonic Mean

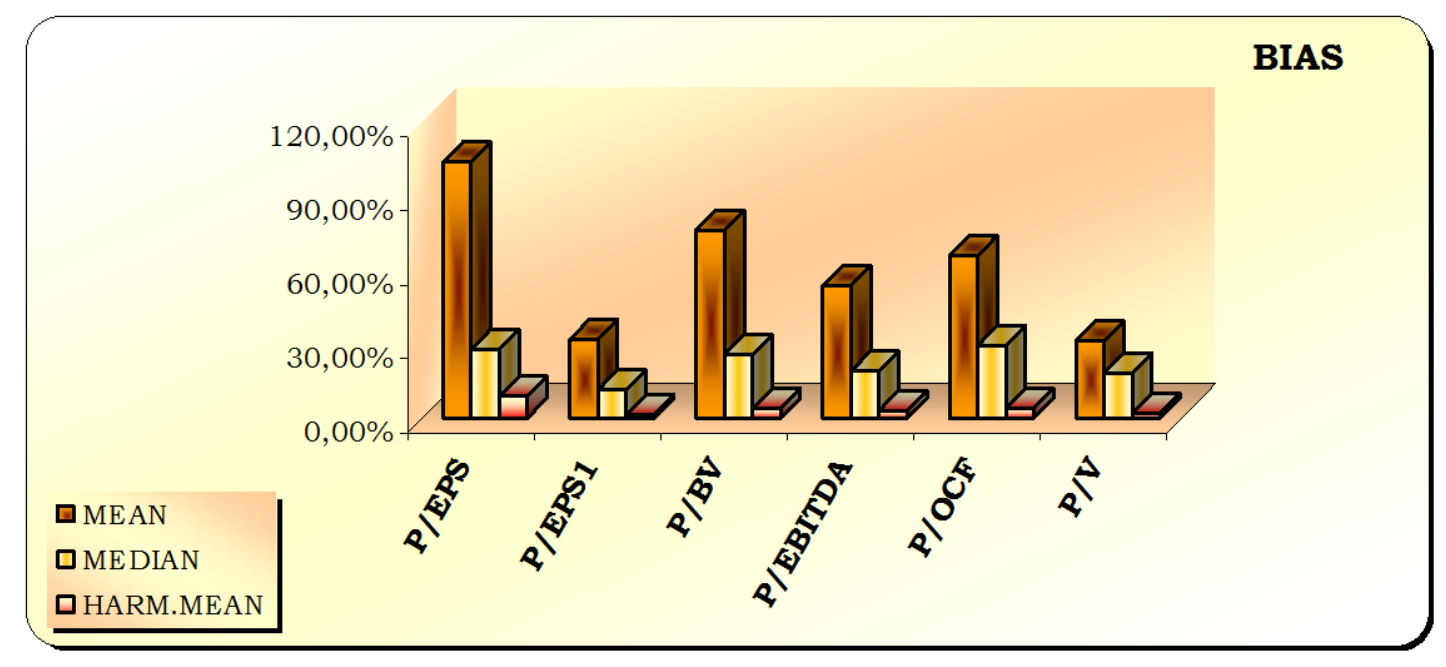

Figure 6. Comparison of the Average Bias of the Different Multiples, Computed with the Mean, Median and the Harmonic Mean

These findings are consistent with those of Baker and Ruback (1999), who suggest that the harmonic mean yield more accurate estimates.

\subsection{Comparison of Pricing-Multiples between industries}

As the value estimates derived from the harmonic mean are better predictors of the market prices, I choose to examine only these estimates for comparison purposes. 
Panel A and Panel B of Table 5 and Table 6 present respectively the average and median accuracy and bias of the diverse multiple approaches for the 17 industries that consist my sample.

It is observed from table 5 that values based on the EPS are better predictors of the market price for more than half of the industries. Between current and forecasted EPS, the forecasted ones perform better for more industries (the EPS1 is more accurate in 9 of the cases while the current EPS in 6). For the Media \& Entertainment (MEDIA) and the Construction \& Building Materials (CNSBM) sectors only, the preferred value driver is EBITDA. This happens because these sectors have a lot of exceptional items and bottom-line earnings do not reflect real value. Furthermore, although the multiples based on the value derived from the RIVM are associated with share prices, they improve the performance of earnings in only two cases.

Table 5. Panel A: Comparison of the average accuracy of each model for the various industries. Panel B: Comparison of the average bias of each model for the various industries

\begin{tabular}{|c|c|c|c|c|c|c|}
\hline \multirow[b]{2}{*}{ INDUSTRY } & \multicolumn{6}{|c|}{ PRICING-MULTIPLES } \\
\hline & P/EPS & P/EPS1 & P/BV & P/EBITDA & P/OCF & $\mathbf{P} / \mathbf{V}$ \\
\hline AUTMB & $32.27 \%$ & $16.63 \%$ & $72.50 \%$ & $62.10 \%$ & $54.45 \%$ & $28.02 \%$ \\
\hline BEVES & $17.99 \%$ & $16.42 \%$ & $55.71 \%$ & $28.36 \%$ & $45.83 \%$ & $15.92 \%$ \\
\hline CHMCL & $37.68 \%$ & $41.57 \%$ & $59.83 \%$ & $49.83 \%$ & $51.96 \%$ & $38.97 \%$ \\
\hline CNSBM & $34.42 \%$ & $35.93 \%$ & $43.67 \%$ & $28.71 \%$ & $46.75 \%$ & $40.17 \%$ \\
\hline ELTNC & $24.66 \%$ & $32.92 \%$ & $47.06 \%$ & $29.10 \%$ & $50.05 \%$ & $51.14 \%$ \\
\hline ENGEN & $24.24 \%$ & $35.50 \%$ & $52.15 \%$ & $33.92 \%$ & $37.81 \%$ & $47.70 \%$ \\
\hline FDRET & $35.77 \%$ & $27.12 \%$ & $83.84 \%$ & $97.00 \%$ & $109.51 \%$ & $32.58 \%$ \\
\hline FOODS & $22.84 \%$ & $23.17 \%$ & $67.10 \%$ & $33.41 \%$ & $46.61 \%$ & $28.99 \%$ \\
\hline HHOLD & $86.78 \%$ & $39.65 \%$ & $49.49 \%$ & $67.68 \%$ & $71.14 \%$ & $54.80 \%$ \\
\hline HLTHC & $48.00 \%$ & $43.97 \%$ & $82.78 \%$ & $58.69 \%$ & $52.35 \%$ & $40.61 \%$ \\
\hline LESUR & $31.98 \%$ & $27.02 \%$ & $40.29 \%$ & $33.32 \%$ & $33.40 \%$ & $31.71 \%$ \\
\hline MEDIA & $105.08 \%$ & $91.65 \%$ & $96.86 \%$ & $83.96 \%$ & $101.24 \%$ & $89.36 \%$ \\
\hline OILGS & $52.24 \%$ & $33.07 \%$ & $44.31 \%$ & $52.33 \%$ & $60.03 \%$ & $52.21 \%$ \\
\hline RTAIL & $30.13 \%$ & $28.27 \%$ & $66.89 \%$ & $36.82 \%$ & $46.46 \%$ & $40.52 \%$ \\
\hline SFTCS & $47.13 \%$ & $35.29 \%$ & $52.24 \%$ & $44.70 \%$ & $46.86 \%$ & $53.87 \%$ \\
\hline SUPSV & $131.03 \%$ & $39.51 \%$ & $47.12 \%$ & $60.05 \%$ & $68.60 \%$ & $42.36 \%$ \\
\hline TRNSP & $23.78 \%$ & $32.37 \%$ & $52.78 \%$ & $42.23 \%$ & $46.31 \%$ & $38.08 \%$ \\
\hline
\end{tabular}




\begin{tabular}{l|cccccc} 
INDUSTRY & P/EPS & P/EPS1 & P/BV & P/EBITDA & P/OCF & P/V \\
\hline AUTMB & $2.85 \%$ & $0.90 \%$ & $12.17 \%$ & $9.87 \%$ & $8.42 \%$ & $2.11 \%$ \\
BEVES & $0.58 \%$ & $0.51 \%$ & $6.42 \%$ & $1.48 \%$ & $3.71 \%$ & $0.71 \%$ \\
CHMCL & $2.42 \%$ & $2.75 \%$ & $5.92 \%$ & $3.68 \%$ & $2.91 \%$ & $1.87 \%$ \\
CNSBM & $0.47 \%$ & $0.51 \%$ & $0.84 \%$ & $0.44 \%$ & $1.06 \%$ & $0.59 \%$ \\
ELTNC & $0.90 \%$ & $1.53 \%$ & $2.96 \%$ & $1.35 \%$ & $4.06 \%$ & $4.91 \%$ \\
ENGEN & $0.72 \%$ & $1.18 \%$ & $3.02 \%$ & $1.21 \%$ & $1.71 \%$ & $2.40 \%$ \\
FDRET & $2.50 \%$ & $1.63 \%$ & $16.42 \%$ & $26.45 \%$ & $32.53 \%$ & $2.23 \%$ \\
FOODS & $0.55 \%$ & $0.61 \%$ & $6.09 \%$ & $1.17 \%$ & $2.19 \%$ & $1.38 \%$ \\
HHOLD & $15.60 \%$ & $4.11 \%$ & $3.47 \%$ & $7.09 \%$ & $8.18 \%$ & $5.91 \%$ \\
HLTHC & $3.99 \%$ & $2.67 \%$ & $10.68 \%$ & $5.23 \%$ & $4.20 \%$ & $3.01 \%$ \\
LESUR & $0.44 \%$ & $0.52 \%$ & $0.75 \%$ & $0.48 \%$ & $0.51 \%$ & $0.54 \%$ \\
MEDIA & $16.67 \%$ & $9.18 \%$ & $11.80 \%$ & $12.35 \%$ & $19.81 \%$ & $10.26 \%$ \\
OILGS & $4.31 \%$ & $2.26 \%$ & $2.32 \%$ & $5.67 \%$ & $6.41 \%$ & $5.67 \%$ \\
RTAIL & $0.41 \%$ & $0.33 \%$ & $4.57 \%$ & $0.69 \%$ & $0.86 \%$ & $0.81 \%$ \\
SFTCS & $1.59 \%$ & $1.01 \%$ & $2.91 \%$ & $1.37 \%$ & $1.56 \%$ & $2.64 \%$ \\
SUPSV & $38.56 \%$ & $0.46 \%$ & $1.05 \%$ & $2.08 \%$ & $2.64 \%$ & $0.46 \%$ \\
TRNSP & $0.47 \%$ & $0.94 \%$ & $2.95 \%$ & $1.65 \%$ & $1.72 \%$ & $1.31 \%$ \\
\hline
\end{tabular}

Panel $A$ of this table shows the average APE of the various multiples for the different industries and Panel B the average SPE of the same multiples for the same industries. Industries are classified with the INDC4 as provided by Datastream. P is the observed stock price and $V$ is the intrinsic value estimated using the RI model. All the other variables are obtained from Datastream. EPS is the earnings per share (211), EPS1 is the 1-year ahead forecasted EPS, BV is the closing shareholders funds (1107), EBITDA (1502) and OCF (1015). In order to convert the above Datastream items but $B V$ in a per share basis, the weighted average number of shares was used, which is the quotient of the Datastream items 210/211. The BV was divided by the number of shares provided by Datastream (IC), to obtain the per share value.

Table 5 and 6 indicate that there is no evidence of a preferred multiple for all the industries, as the median SPE and APE vary largely across industries.

These findings are consistent with Baker and Ruback (1999), Tasker (1998) and Liu et al. (2002b) in that there does not exist a dominant value driver for all the industries. In addition, I agree with Lee and Swaminathan (1999) in that value estimates based on value calculated using the RIVM are accurate, although I advocate that value estimates based on earnings forecasts outperform the former ${ }^{11}$.

${ }^{11}$ Consistent with Liu et al. (2002a). 
Table 6. Panel A: Comparison of the Median accuracy of each model for the various industries. Panel B: Comparison of the Median bias of each model for the various industries

\begin{tabular}{l|cccccc}
\hline \multicolumn{7}{c}{ VALUATION MODELS } \\
\cline { 2 - 7 } INDUSTRY & P/EPS & P/EPS1 & P/BV & P/EBITDA & P/OCF & P/V \\
\hline AUTMB & $23.48 \%$ & $6.93 \%$ & $45.82 \%$ & $35.55 \%$ & $32.69 \%$ & $14.84 \%$ \\
BEVES & $13.32 \%$ & $15.60 \%$ & $57.48 \%$ & $24.36 \%$ & $47.30 \%$ & $7.68 \%$ \\
CHMCL & $21.32 \%$ & $34.91 \%$ & $48.84 \%$ & $43.16 \%$ & $49.00 \%$ & $35.31 \%$ \\
CNSBM & $41.44 \%$ & $37.14 \%$ & $39.08 \%$ & $17.60 \%$ & $31.77 \%$ & $40.55 \%$ \\
ELTNC & $22.72 \%$ & $34.11 \%$ & $40.98 \%$ & $27.25 \%$ & $31.62 \%$ & $31.54 \%$ \\
ENGEN & $22.90 \%$ & $26.29 \%$ & $37.34 \%$ & $24.22 \%$ & $23.94 \%$ & $39.23 \%$ \\
FDRET & $32.04 \%$ & $25.33 \%$ & $51.61 \%$ & $49.60 \%$ & $51.09 \%$ & $22.08 \%$ \\
FOODS & $27.59 \%$ & $20.25 \%$ & $51.23 \%$ & $32.69 \%$ & $40.70 \%$ & $14.51 \%$ \\
HHOLD & $44.56 \%$ & $14.66 \%$ & $51.24 \%$ & $55.54 \%$ & $58.71 \%$ & $41.61 \%$ \\
HLTHC & $35.78 \%$ & $35.30 \%$ & $64.86 \%$ & $55.34 \%$ & $53.80 \%$ & $29.97 \%$ \\
LESUR & $30.15 \%$ & $22.47 \%$ & $28.93 \%$ & $30.44 \%$ & $28.47 \%$ & $24.66 \%$ \\
MEDIA & $56.28 \%$ & $60.99 \%$ & $80.12 \%$ & $45.30 \%$ & $59.90 \%$ & $51.05 \%$ \\
OILGS & $35.20 \%$ & $17.90 \%$ & $43.24 \%$ & $31.01 \%$ & $33.98 \%$ & $31.32 \%$ \\
RTAIL & $24.36 \%$ & $23.63 \%$ & $41.41 \%$ & $26.89 \%$ & $39.60 \%$ & $33.18 \%$ \\
SFTCS & $44.69 \%$ & $27.85 \%$ & $38.60 \%$ & $40.82 \%$ & $37.27 \%$ & $48.00 \%$ \\
SUPSV & $50.95 \%$ & $30.88 \%$ & $33.40 \%$ & $36.33 \%$ & $46.84 \%$ & $37.74 \%$ \\
TRNSP & $19.07 \%$ & $22.93 \%$ & $33.70 \%$ & $41.26 \%$ & $44.27 \%$ & $28.32 \%$ \\
\hline
\end{tabular}

VALUATION MODELS

PRICING-MULTIPLES

\begin{tabular}{l|cccccc}
\cline { 2 - 7 } INDUSTRY & P/EPS & P/EPS1 & P/BV & P/EBITDA & P/OCF & P/V \\
\hline AUTMB & $15.40 \%$ & $4.97 \%$ & $-44.83 \%$ & $-29.28 \%$ & $-32.46 \%$ & $-8.56 \%$ \\
BEVES & $10.94 \%$ & $-5.12 \%$ & $-16.77 \%$ & $3.78 \%$ & $16.48 \%$ & $-1.37 \%$ \\
CHMCL & $-7.62 \%$ & $-7.18 \%$ & $-16.64 \%$ & $-10.00 \%$ & $-14.74 \%$ & $-12.28 \%$ \\
CNSBM & $-1.23 \%$ & $-7.44 \%$ & $-4.98 \%$ & $-0.58 \%$ & $-15.19 \%$ & $0.76 \%$ \\
ELTNC & $-8.32 \%$ & $-12.06 \%$ & $-19.33 \%$ & $3.77 \%$ & $-18.49 \%-26.96 \%$ \\
ENGEN & $-2.34 \%$ & $-16.38 \%$ & $-23.02 \%$ & $-9.11 \%$ & $-13.51 \%$ & $-2.56 \%$ \\
FDRET & $-15.51 \%$ & $-7.25 \%$ & $-24.21 \%$ & $-31.44 \%$ & $-34.90 \%-15.34 \%$ \\
FOODS & $0.10 \%$ & $-1.91 \%$ & $-28.92 \%$ & $-7.59 \%$ & $-15.66 \%$ & $-3.03 \%$ \\
HHOLD & $-23.33 \%$ & $-4.37 \%$ & $3.74 \%$ & $-31.26 \%$ & $-23.34 \%-37.82 \%$ \\
HLTHC & $-25.74 \%$ & $-0.69 \%$ & $-42.48 \%$ & $-20.52 \%$ & $-20.58 \%$ & $-9.17 \%$ \\
LESUR & $-5.04 \%$ & $-1.97 \%$ & $-11.37 \%$ & $-0.78 \%$ & $-10.82 \%$ & $-9.28 \%$ \\
MEDIA & $-51.36 \%$ & $-49.20 \%$ & $-27.34 \%$ & $-40.96 \%$ & $-49.42 \%$ & $-48.55 \%$ \\
OILGS & $-21.27 \%$ & $-11.74 \%$ & $13.55 \%$ & $-19.36 \%$ & $-22.94 \%-19.42 \%$ \\
RTAIL & $0.64 \%$ & $-0.36 \%$ & $-23.94 \%$ & $-8.00 \%$ & $-3.89 \%$ & $-6.04 \%$
\end{tabular}




\begin{tabular}{|c|c|c|c|c|c|}
\hline SFTCS & $-0.93 \%$ & $-8.58 \%$ & $-24.08 \%$ & $-18.75 \%$ & $-12.86 \%-25.79 \%$ \\
\hline SUPSV & $-49.45 \%$ & $-3.29 \%$ & $-11.16 \%$ & $-27.83 \%$ & $-33.38 \%-13.92 \%$ \\
\hline TRNSP & $-3.11 \%$ & $-4.37 \%$ & $-21.71 \%$ & $1.17 \%$ & $-6.63 \%-5.99 \%$ \\
\hline
\end{tabular}

Panel A of this table shows the median APE of the various multiples for the different industries and Panel B the median SPE of the same multiples for the same industries. Industries are classified with the INDC4 as provided by Datastream. P is the observed stock price and $V$ is the intrinsic value estimated using the RI model. All the other variables are obtained from Datastream. EPS is the earnings per share (211), EPS1 is the 1-year ahead forecasted EPS, BV is the closing shareholders' funds (1107), EBITDA (1502) and OCF (1015). In order to convert the above Datastream items but $B V$ in a per share basis, the weighted average number of shares was used, which is the quotient of the division of Datastream items 210/211. The $B V$ was divided by the number of shares provided by Datastream (IC), to obtain the per share value.

In summary, despite the fact that the earnings multiples show an increased performance, the evidence suggests that there are certain multiples that are better for some industries, and no value driver is best for all the industries.

\subsection{Comparison between the RIVM and the pricing-multiple approach}

In order to provide a more complete evaluation of the two methods, I compare the average and median performance of the value estimates derived from the RIVM with those derived from the pricing-multiples model. For simplicity reasons, I decide not to include all the pricing-multiples approaches, but only the ones that perform better in each case and for each industry. The model that is considered superior is the one with the smaller average or median values of the SPE and APE, in proportion to what is measured ${ }^{12}$.

Table 7 shows the average APE and SPE for the two valuation methods examined and for the different industries of my sample. It indicates that the RIVM is more accurate than the pricing-multiples model in only one sector, the Media \& Entertainment (MEDIA). Additionally, the RIVM gives more biased estimates than the multiples approach. Only for the Media \& Entertainment sector the SPE of the two approaches is similar.

Table 7. Comparison of the Average Accuracy and Bias of the RIVM and the Pricing-Multiples Model

\section{Panel A: Accuracy}

${ }^{12}$ For example, for the Chemicals industry, the average APE found with the RIVM is compared with the lowest of the average APE 's derived from the diverse multiples. In this case, this is the value computed with a multiple based on the current EPS. 


\begin{tabular}{l|ll|ll}
\multicolumn{5}{c}{} \\
\cline { 2 - 5 } INDUSTRY & RIVM & PRICING MULTIPLES & \multicolumn{1}{c}{ VD } & DIFFERENCE \\
\hline AUTMB & $97.54 \%$ & $16.63 \%$ & EPS1 & $80.91 \%$ \\
BEVES & $40.35 \%$ & $15.92 \%$ & V & $24.44 \%$ \\
CHMCL & $52.05 \%$ & $37.68 \%$ & EPS & $14.37 \%$ \\
CNSBM & $96.93 \%$ & $28.71 \%$ & EBITDA & $68.21 \%$ \\
ELTNC & $43.55 \%$ & $24.66 \%$ & EPS & $18.89 \%$ \\
ENGEN & $71.98 \%$ & $24.24 \%$ & EPS & $47.75 \%$ \\
FDRET & $60.81 \%$ & $27.12 \%$ & EPS1 & $33.68 \%$ \\
FOODS & $101.55 \%$ & $22.84 \%$ & EPS & $78.71 \%$ \\
HHOLD & $174.90 \%$ & $39.65 \%$ & EPS1 & $135.25 \%$ \\
HLTHC & $41.83 \%$ & $40.61 \%$ & V & $1.22 \%$ \\
LESUR & $72.33 \%$ & $27.02 \%$ & EPS1 & $45.32 \%$ \\
MEDIA & $80.18 \%$ & $83.96 \%$ & EBITDA & $-3.78 \%$ \\
OILGS & $70.50 \%$ & $33.07 \%$ & EPS1 & $37.43 \%$ \\
RTAIL & $80.05 \%$ & $28.27 \%$ & EPS1 & $51.78 \%$ \\
SFTCS & $53.05 \%$ & $35.29 \%$ & EPS1 & $17.76 \%$ \\
SUPSV & $50.19 \%$ & $39.51 \%$ & EPS1 & $10.68 \%$ \\
TRNSP & $56.08 \%$ & $23.78 \%$ & EPS & $32.29 \%$ \\
\hline
\end{tabular}

Panel B: Bias

\begin{tabular}{l|c|c|lc}
\multicolumn{2}{c}{ VALUATION MODELS } \\
INDUSTRY & RIVM & PRICING MULTIPLES & \multicolumn{1}{c}{ VD } & DIFFERENCE \\
\hline AUTMB & $94.79 \%$ & $0.90 \%$ & EPS1 & $93.89 \%$ \\
BEVES & $39.63 \%$ & $0.51 \%$ & EPS1 & $39.12 \%$ \\
CHMCL & $40.26 \%$ & $1.87 \%$ & V & $38.38 \%$ \\
CNSBM & $90.89 \%$ & $0.44 \%$ & EBITDA & $90.45 \%$ \\
ELTNC & $4.91 \%$ & $0.90 \%$ & EPS & $4.01 \%$ \\
ENGEN & $57.32 \%$ & $0.72 \%$ & EPS & $56.60 \%$ \\
FDRET & $60.81 \%$ & $1.63 \%$ & EPS1 & $59.18 \%$ \\
FOODS & $98.97 \%$ & $0.55 \%$ & EPS & $98.41 \%$ \\
HHOLD & $174.90 \%$ & $3.47 \%$ & BV & $171.42 \%$ \\
HLTHC & $20.47 \%$ & $2.67 \%$ & EPS1 & $17.81 \%$ \\
LESUR & $68.99 \%$ & $0.44 \%$ & EPS & $68.55 \%$ \\
MEDIA & $9.78 \%$ & $9.18 \%$ & EPS1 & $0.61 \%$ \\
OILGS & $59.29 \%$ & $2.26 \%$ & EPS1 & $57.02 \%$ \\
RTAIL & $66.45 \%$ & $0.33 \%$ & EPS1 & $66.12 \%$
\end{tabular}




\begin{tabular}{l|llll} 
SFTCS & $16.92 \%$ & $1.01 \%$ & EPS1 & $15.92 \%$ \\
SUPSV & $22.80 \%$ & $0.46 \%$ & V & $22.34 \%$ \\
TRNSP & $37.07 \%$ & $0.47 \%$ & EPS & $36.60 \%$ \\
\hline
\end{tabular}

Panel A of the table presents the average APE of the RIVM and the pricing-multiples and Panel B the average SPE for the various industries classified as the Datastream INDC4. For the pricing-multiples approach, the multiple selected is the one that has the lowest accuracy and bias for each industry. The specific value driver of each multiple is shown in the column VD. The last column shows the difference between the two models for comparison purposes.

Table 8 presents the median accuracy and bias of both the RIVM and the pricingmultiples for each industry. As in table 7, for the pricing-multiples approach, the value driver used in each industry is the one that yields the best estimates. The findings are similar to the ones derived when average accuracy and bias is measured. Only for the Media \& Entertainment sector, the RIVM yields more accurate estimates. Besides, when values are computed with the multiples approach, the median SPE 's are closer to zero for all the industries, than when computed with the RIVM.

Table 8. Comparison of the Median Accuracy and Bias of the RIVM and the Pricing-Multiples Model

\begin{tabular}{|c|c|c|c|c|}
\hline \multicolumn{4}{|c|}{ Panel A: Accuracy } & \multirow[b]{3}{*}{ DIFFERENCE } \\
\hline \multicolumn{4}{|c|}{ VALUATION MODELS } & \\
\hline INDUSTRY & RIVM & PRICING MULTIPLES & VD & \\
\hline AUTMB & $80.33 \%$ & $6.93 \%$ & EPS1 & $73.40 \%$ \\
\hline BEVES & $37.99 \%$ & $7.68 \%$ & $\mathbf{V}$ & $30.30 \%$ \\
\hline CHMCL & $33.89 \%$ & $21.32 \%$ & EPS & $12.57 \%$ \\
\hline CNSBM & $92.29 \%$ & $17.60 \%$ & EBITDA & $74.69 \%$ \\
\hline ELTNC & $26.69 \%$ & $22.72 \%$ & EPS & $3.97 \%$ \\
\hline ENGEN & $53.52 \%$ & $22.90 \%$ & EPS & $30.62 \%$ \\
\hline FDRET & $39.19 \%$ & $22.08 \%$ & $\mathbf{V}$ & $17.11 \%$ \\
\hline FOODS & $93.40 \%$ & $14.51 \%$ & $\mathbf{V}$ & $78.89 \%$ \\
\hline HHOLD & $78.43 \%$ & $14.66 \%$ & EPS1 & $63.77 \%$ \\
\hline HLTHC & $36.49 \%$ & $29.97 \%$ & V & $6.52 \%$ \\
\hline LESUR & $53.70 \%$ & $22.47 \%$ & EPS1 & $31.23 \%$ \\
\hline MEDIA & $44.86 \%$ & $45.30 \%$ & EBITDA & $\underline{-0.44 \%}$ \\
\hline OILGS & $30.65 \%$ & $17.90 \%$ & EPS1 & $\overline{12.75 \%}$ \\
\hline RTAIL & $58.69 \%$ & $23.63 \%$ & EPS1 & $35.06 \%$ \\
\hline SFTCS & $38.21 \%$ & $27.85 \%$ & EPS1 & $10.36 \%$ \\
\hline SUPSV & $39.45 \%$ & $30.88 \%$ & EPS1 & $8.57 \%$ \\
\hline TRNSP & $34.59 \%$ & $19.07 \%$ & EPS & $15.52 \%$ \\
\hline
\end{tabular}

Panel B: Bias 


\begin{tabular}{l|cclc}
\multicolumn{2}{c}{ INDUSTRY } & \multicolumn{2}{l}{ RALUATION MODELS } & \\
\cline { 2 - 4 } AUTMB & $80.33 \%$ & \multicolumn{1}{c}{ PRICING MULTIPLES } & \multicolumn{1}{c}{ VD } & DIFFERENCE \\
BUEVES & $37.99 \%$ & $4.97 \%$ & EPS1 & $75.36 \%$ \\
CHMCL & $24.20 \%$ & $-1.37 \%$ & V & $39.36 \%$ \\
CNSBM & $92.29 \%$ & $-7.18 \%$ & EPS1 & $31.38 \%$ \\
ELTNC & $-21.01 \%$ & $-0.58 \%$ & EBITDA & $92.87 \%$ \\
ENGEN & $53.52 \%$ & $3.77 \%$ & EBITDA & $-24.77 \%$ \\
FDRET & $39.19 \%$ & $-2.34 \%$ & EPS & $55.85 \%$ \\
FOODS & $93.40 \%$ & $-7.25 \%$ & EPS1 & $46.44 \%$ \\
HHOLD & $78.43 \%$ & $0.10 \%$ & EPS & $93.29 \%$ \\
HLTHC & $10.29 \%$ & $3.74 \%$ & BV & $74.69 \%$ \\
LESUR & $53.70 \%$ & $-0.69 \%$ & EPS1 & $10.98 \%$ \\
MEDIA & $-42.11 \%$ & $-0.78 \%$ & EBITDA & $54.48 \%$ \\
OILGS & $30.65 \%$ & $-27.34 \%$ & BV & $-14.77 \%$ \\
RTAIL & $56.65 \%$ & $-11.74 \%$ & EPS1 & $42.39 \%$ \\
SFTCS & $-12.15 \%$ & $-0.36 \%$ & EPS1 & $57.01 \%$ \\
SUPSV & $5.97 \%$ & $-0.93 \%$ & EPS & $-11.22 \%$ \\
TRNSP & $29.25 \%$ & $-3.29 \%$ & EPS1 & $9.26 \%$ \\
\hline
\end{tabular}

Panel A of the table presents the median APE of the RIVM and the pricing-multiples and Panel B the median SPE for the various industries classified as the Datastream INDC4. For the pricing-multiples approach, the multiple selected is the one that has the lowest accuracy and bias for each industry. The specific value driver of each multiple is shown in the column VD. The last column shows the difference between the two models for comparison purposes.

In summary, the results of my tests show that the RIVM does not generate accurate and unbiased predictors of the prices comparing to the pricing-multiples valuation model, when the latter are computed with the harmonic mean. Moreover, there does not exist a single value driver that performs best in all the industries.

\section{Conclusion}

In this paper, I test the performance of the RIVM and whether the performance of the different multiples increases when these are measured either with the mean, the median or the harmonic mean. My aim is to test how the RIVM performs relative to the pricing-multiples approach for a set of different value drivers and industries. My motivation for these tests is the fact that there does not exist any previous study, which compares directly the RIVM with the pricing-multiple approach for different industries.

The results of my statistical tests can be summarized as follows. The value drivers computed with the harmonic mean yield to more reliable estimates of value for all the different industries comparing to those computed with the mean or the median. In addition, there exist some value drivers that are more reliable than others. These 
value drivers vary from industry to industry because of the fundamental differences that exist between industries. There is no evidence of one value driver that leads to the most reliable estimates in all the industries. Finally, the pricing-multiples approach computed with the harmonic mean is in most cases a better predictor of the market prices than the RIVM. The values derived from the pricing - multiples model are more accurate and less biased than those derived from the RIVM. However, this evidence is not absolute because the selected sample is based on many assumptions.

\section{References}

Alford, A., 1992. The Effect of the Set of Comparable Firms on the Accuracy of the Price-Earnings Valuation Method. Journal of Accounting Research, Vol. 30 Issue 1: pp94-108.

Baker, M. and Ruback, R., 1999. Estimating Industry Multiples. Working Paper, Harvard University.

Barth, M., Beaver, W. and Landsman, W., 1992. The Market Valuation Implications of Net Periodic Pension Cost Components. Journal of Accounting \& Economics, Vol. 15: pp27-62.

Basu, S., 1997. The Conservatism Principle and the Asymmetric Timeliness of Earnings. Journal of Accounting \& Economics, Vol. 24: pp3-37.

Beatty, R., Riffe, S., Thompson, R., 1999. The method of Comparables and Tax Court Valuations of Private: An Empirical Investigation. Accounting Horizons, Vol. 13, Issue 3: pp177-199.

Beaver, W. and Ryan, S., 2000. Biases and Lags in Book Value and their Effects on the Ability of the Book-to-Market Ratio to Predict Book Rate of Return on Equity. Journal of Accounting Research, Vol. 38: pp127-148.

Bernard, V., 1995. The Feltham-Ohlson Framework: Implications for Empiricists. Contemporary Accounting Research, Vol. 11: pp733-747.

Copeland, T., Koller, T. and Murrin, M., 2000. Valuation: Measuring and Managing the Value of Companies, $3^{\text {rd }}$ Edition, Wiley.

Dechow, P., Hutton, A., Sloan, R., 1999. An Empirical Assessment of the Residual Income Valuation Model. Journal of Accounting \& Economics, Vol. 26: pp1-34.

Dimson, E., Marsh P. and Staunton M., 2003. Global Evidence on the Equity Risk Premium. Journal of Applied Corporate Finance, forthcoming.

Easton, P. 1999. Security Returns and the Value Relevance of Accounting Data. Accounting Horizons, Vol. 13, Issue 4: pp.399-412.

Fama, E. and French K., 2000. Forecasting Profitability and Earnings. Journal of Business, forthcoming.

Feltham, G. and Ohlson, J., 1995. Valuation and Clean Surplus Accounting for Operating and Financial Activities. Contemporary Accounting Research, Vol. 11: pp689-731.

Francis, J., Olson, P. and Oswald, D., 2000. Comparing the Accuracy and Explainability of Dividend, Free Cash Flow and Abnormal Earnings Equity 
Valuation Estimates. Journal of Accounting Research, Vol.38, Issue 1: pp4570.

Frankel, R. and Lee, C., 1998. Accounting Valuation, Market Expectation, and Cross-Sectional Stock Returns. Journal of Accounting \& Economics, Vol. 25, Issue 3: pp283-319.

Gilson, S., Hotchkiss, E. and Ruback, R., 2000. Valuation of Bankrupt Firms. Review of Financial Studies, Vol. 13, Issue 1: pp43-74.

Gordon, M., 1962. The Investment, Financing, and Valuation of the Corporation, Richard D. Irwin Inc. Homewood, Il.

Kaplan, S. and Ruback, R., 1995. The Valuation of Cash Flow Forecasts: An Empirical Analysis. Journal of Finance, Vol. 50, Issue 4: pp1059-1093.

Kim, M. and Ritter, J., 1999. Valuing IPOs. Journal of Financial Economics, Vol. 53: pp.409-437.

Kothari, S.P., 2001. Capital Markets Research in Accounting. Journal of Accounting \& Economics, Vol. 31, Issue 1-3: pp. 105-232.

Lee, C., Myers, J. and Swaminathan, B., 1999. What is the Intrinsic Value of the Dow? Journal of Finance, Vol. 54: pp1693-1741.

Lee, C. and Swaminathan, B. 1999. Valuing the Dow: A Bottom-Up Approach. Financial Analysts Journal, Vol. 55, Issue 5: pp4-23.

Liu, J., Nissim, D. and Thomas, J., 2002a. Equity Valuation Using Multiples. Journal of Accounting Research, Vol. 40, Issue 1: pp135-171.

Liu, J., Nissim, D. and Thomas, J., 2002b. International Equity Valuation Using Multiples. Working Paper, University of Columbia.

Livnat, J. and Zarowin, P., 1990. The incremental Information Content of Cash-flow Components. Journal of Accounting \& Economics, Vol. 13: pp25-46.

Lundholme, R. and O' Keefe, T., 2001. Reconciling Value Estimates from the Discounted Cash Flow Model and the Residual Income Model. Contemporary Accounting Research, Vol.18, Issue 2: pp311-335.

O'Hanlon, J. and Steele, A., 2000. Estimating the Equity Risk Premium Using Accounting Fundamentals. Journal of Business Finance \& Accounting, Vol. 27, Issue 9/10: pp1051-1084.

Ohlson, J., 1995. Earnings, Book Values, and Dividends in Equity Valuation. Contemporary Accounting Research, Vol. 11: pp661-687.

Penman, S., 1996. The Articulation of Price-earnings Ratios and Market-to-book Ratios and the Evaluation of Growth. Journal of Accounting Research, Vol. 34: pp235-259.

Penman, S., 1998. Combining Earnings and Book Values in Equity Valuation. Contemporary Accounting Research, Vol. 15: pp291-324.

Penman, S. and Sougiannis, T., 1998. A Comparison of Dividend, Cash Flow, and Earnings Approaches to Equity Valuation. Contemporary Accounting Research, Vol. 15: pp343-383.

Ryan, S., 1995. A Model of Accrual Measurement with Implications for the Evolution of the Book-to-market Ratio. Journal of Accounting Research, Vol. 29: pp95-112. 
Tasker, S., 1999. Industry Preferred Multiples in Acquisition Valuation. Working Paper, Cornell University.

Verrecchia, R., 1998. Discussion of Accrual Accounting and Equity Valuation. Journal of Accounting Research Supplement, Vol. 36: pp113-115.

Walker, M. 1997. Clean Surplus Accounting Models and Market-based Accounting Research: A Review. Accounting and Business Research, Vol. 27, Issue 4: pp.341-355.

Zhang, X., 1999. Conservative Accounting and Equity Valuation. Working Paper, University of California, Berkeley.

\section{APPENDIX A}

Figure 3: Median Signed Prediction Error

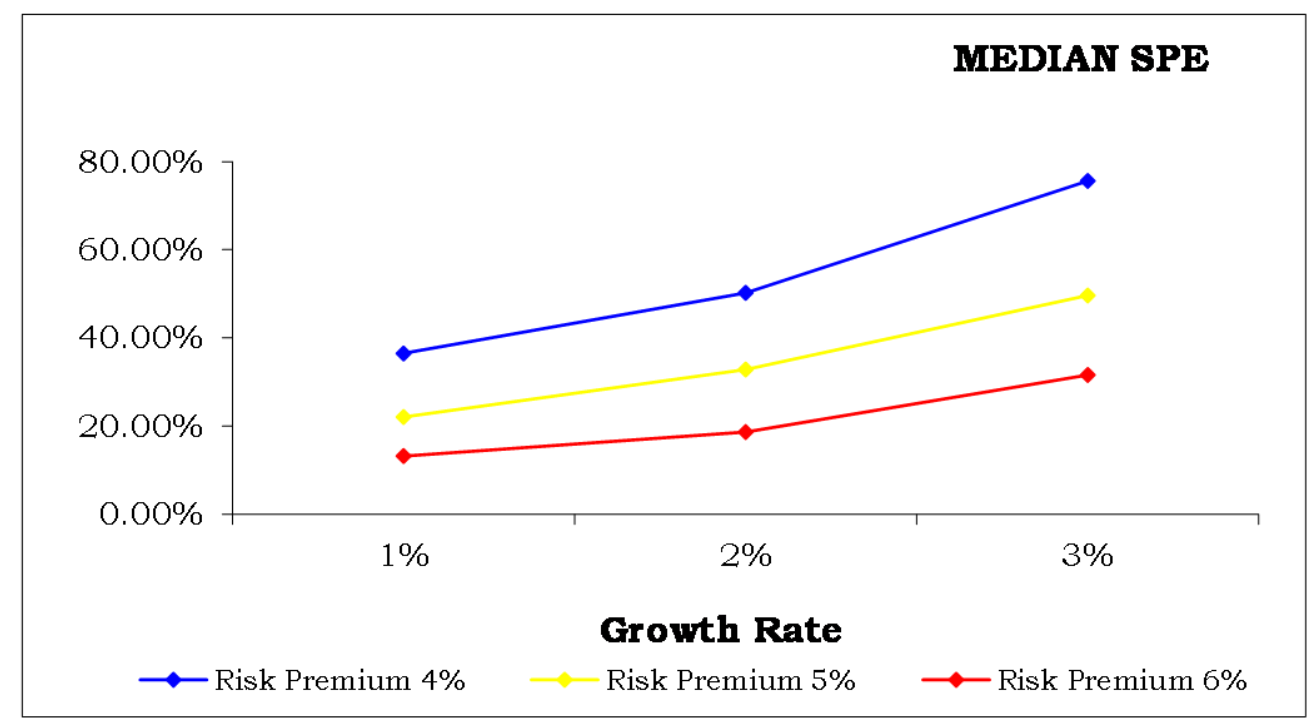

Figure 4: Median Absolute Prediction Errors 


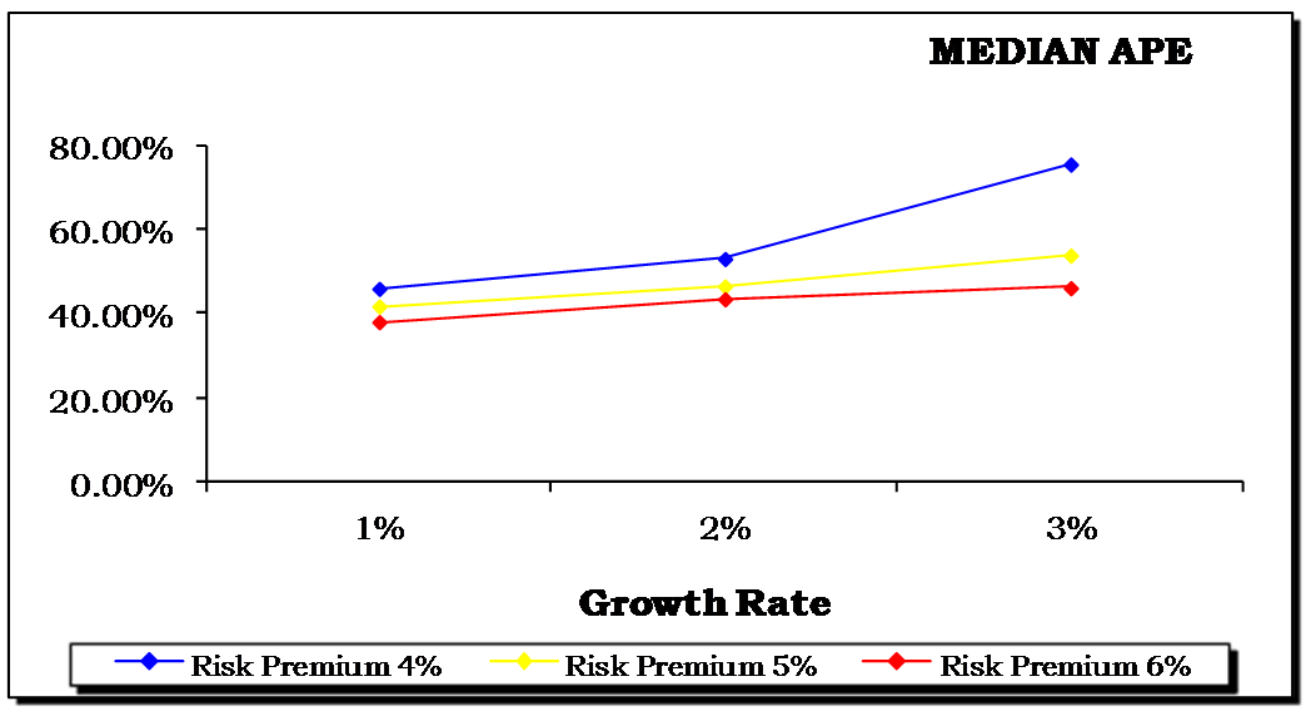

